\title{
FRAUD DALAM PROSES AKADEMIK PADA PERILAKU MAHASISWA
}

\begin{abstract}
An interesting phenomenon to observe in the world of education today is the discovery of fraudulent practices called academic fraud. This study aims to analyze the effect of fraud in the academic process on student behavior with the fraud pentagon concept. This study uses a quantitative approach and the type of data used in this study is primary data, namely data obtained directly through a questionnaire. The sampling method used was purposive sampling method, namely a method that uses certain criteria. Respondents in this study were active students at 15 University in Bandar Lampung and had or are currently taking courses or Professional Ethics courses related to Ethics. The data processing and analysis technique used is multiple linear regression with hypothesis $T$ test and $F$ test. The results showed that the variables of opportunity, rationalization, and ability have a positive effect on student behavior. Meanwhile, pressure and arrogance variables have on effect on student behavior.
\end{abstract}

Abstrak: Fenomena yang cukup menarik untuk diamati di dalam dunia pendidikan saat ini yaitu banyak ditemukannya praktikpraktik kecurangan (fraud) yang terjadi, hal ini disebut academic fraud. Penelitian ini bertujuan untuk menganalisis pengaruh fraud dalam proses akademik terhadap perilaku mahasiswa yang menggunakan konsep fraud pentagon. Penelitian ini menggunakan pendekatan kuantitatif serta jenis data yang digunakan dalam penelitian ini adalah data primer yaitu data yang diperoleh langsung melalui kuesioner. Metode pengambilan sampel menggunakan metode purposive sampling yaitu metode yang menggunakan kriteria tertentu. Responden dalam penelitian ini adalah mahasiswa aktif di 15 Universitas di Bandar Lampung dan telah atau sedang menempuh matakuliah Etika Profesi atau matakuliah yang berkaitan dengan Etika. Teknik pengolahan dan analisis data yang digunakan adalah regresi linear berganda dengan hipotesis uji $\mathrm{T}$ dan uji $\mathrm{F}$. Hasil penelitian menunjukan bahwa variabel Peluang, Rasionalisasi, dan Kemampuan berpengaruh positif terhadap Perilaku Mahasiswa. Sementara itu, variabel Tekanan dan Arogansi tidak memiliki pengaruh terhadap Perilaku Mahasiswa.

\author{
Maria Tri Kurnia \\ Handayani ${ }^{1}$, Dhiona Ayu \\ Nani $^{2^{*}}$, Vera Apri Dina \\ Safitri $^{3}$
}

1, 2, 3 Akuntansi, Fakultas

Ekonomi Dan Bisnis, Universitas

Teknokrat Indonesia, Kota

Bandar Lampung, Indonesia

dhiona.a@teknokrat.ac.id

Keyword: Academic fraud, Fraud Pentagon

Kata kunci: Kecurangan Akademik, Fraud Pentagon 


\section{Pendahuluan}

Perkembangan zaman di era 4.0 seperti menjunjung tinggi asas kejujuran dengan sekarang ini menuntut adanya sumber daya salah satu cara menghindari kecurangan manusia yang berkualitas tinggi. Peningkatan akademik. Kecurangan akademik dilakukan kualitas sumber daya manusia merupakan karena adanya tekanan yang mempengaruhi prasyarat mutlak untuk mencapai tujuan perilaku seseorang dalam berperilaku curang. pembangunan. Salah satu sarana untuk Tekanan dipengaruhi dari lingkungan mencapai kualitas sumber daya manusia mereka. Sehingga mahasiswa merasa takut tersebut adalah pendidikan. Pendidikan jika tidak melakukan kecurangan akan adalah suatu kekuatan yang sangat mendapatkan hasil/nilai akhir yang jelek. berpengaruh besar terhadap perkembangan Kecurangan akademik terjadi ketika fisik, mental, etika dan seluruh aspek mahasiswa mendapatkan peluang untuk kehidupan manusia. Fenomena yang cukup melakukan hal tersebut. Kecurangan menarik untuk diamati di dalam dunia akademik terjadi saat semakin tinggi tingkat pendidikan yaitu banyak ditemukannya peluang yang dimiliki mahasiswa sehingga praktik-praktik kecurangan (fraud) yang semakin mudah pula kecurangan akademik terjadi, hal ini disebut academic fraud (Putri dilakukan. Kecurangan akademik mahasiswa \& Amar, 2019). Menurut Becker et al. dipengaruhi oleh rasionalisasi atas psikologi (2006) kecurangan akademik (academic seseorang. Implementasi dari rasionalisasi fraud) juga sering ditemukan dalam dunia merupakan keyakinan atas perilaku yang pendidikan khususnya mahasiswa. menjadi suatu dasar seseorang melakukan Kecurangan akademik didefinisikan sebagai kecurangan akademik. Kemudian kecurangan bentuk perilaku yang mendatangkan akademik mahasiswa dipengaruhi oleh keuntungan bagi mahasiswa secara tidak kemampuan yaitu sifat-sifat pribadi dan jujur termasuk didalamnya mencontek, copy kemampuan dalam melakukan kecurangan paste dari internet, bekerjasama dengan akademik. Serta kecurangan akademik teman pada saat ujian, memalsukan sesuatu dipengaruhi oleh arogansi, yaitu sikap yang berhubungan dengan akademik dan superioritas atas hak yang dimiliki dan masih banyak lagi kecurangan lainnya yang merasa bahwa kontrol internal atau kebijakan sering terjadi dan menjadi perilaku yang dalam proses akademik tidak berlaku untuk dapat diterima oleh mahasiswa (Putri \& dirinya.

Amar, 2019).

Undang-Undang No. 12 Tahun 2012 tentang Pendidikan Tinggi pasal 1 ayat 2 diuraikan bahwa pendidikan tinggi adalah jenjang pendidikan setelah pendidikan menengah yang mencakup program diploma, program sarjana, program megister, program doktor, dan program profesi, serta program spesialis, yang diselenggarakan oleh perguruan tinggi berdasarkan kebudayaan bangsa Indonesia. Pada pasal 3 bagian c disebutkan bahwa pendidikan tinggi
Penelitian ini mengisi gap dari penelitian sebelumnya yaitu penelitian Yudiana \& Lastanti (2016) yang menyarankan dilakukannya penilitian serupa dengan memperluas sampel karena penelitian sebelumnya belum bisa mewakili kecurangan akademik yang dilakukan di Universitas lain. Selain itu penelitian ini juga mengisi gap dari penelitian Putri \& Amar (2019) yang menggunakan konsep fraud triangle, di mana penelitian ini memperluas model dengan menggunakan konsep fraud pentagon. 
Kecurangan berasal dari kata "curang" yang dalam Kamus Besar Bahasa Indonesia, curang memiliki arti tidak jujur. Kecurangan akademik didefinisikan sebagai bentuk perilaku yang mendatangkan keuntungan bagi mahasiswa secara tidak jujur termasuk didalamnya mencontek, plagiat, mencuri dan memalsukan sesuatu yang berhubungan dengan akademik (Putri \& Amar, 2019). Menurut Yudiana \& Lastanti (2016) kecurangan akademik dapat diartikan sebagai perilaku yang dilakukan oleh pelajar dengan sengaja, meliputi beberapa bentuk perilaku seperti pelanggaran terhadap aturan dalam penyelesaian tugas dan ujian, memberikan keuntungan kepada pelajar lain dalam mengerjakan tugas atau ujian dengan cara yang tidak jujur, dan pengurangan keakuratan yang diharapkan pada perfomasi belajar

\section{Pengembangan Hipotesis}

Salah satu teori yang berkaitan dengan kecurangan adalah teori fraud pentagon. Teori ini merupakan perluasan dari teori fraud triangle dan teori fraud diamond. Teori ini diperkenalkan dalam literatur pada Horwath (2011) yang berjudul "Why the Fraud Triangle is No Longer Enough" yang dikembangkan oleh Jonathan Marks. Teori ini menambah dua elemen fraud lainnya yaitu kompetensi (competence) dan arogansi (arrogance) ke dalam tiga faktor yang terdapat pada teori fraud triangle. Kompetensi (competence) yang dijelaskan dalam teori fraud pentagon memiliki arti yang serupa dengan kemampuan (capability) yang sebelumnya dijelaskan dalam fraud diamond oleh Wolfe \& Hermanson (2004). Terdapat lima elemen dalam teori fraud oleh kalangan akademisi, penelitian pentagon, yaitu tekanan (pressure), mengenai fraud pentagon masih jarang kesempatan (opportunity), rasionalisasi dilakukan (Ulfah et al, 2017). Penelitin (rationalization), kemampuan (capability) terkait teori fraud pentagon pernah dilakukan dan arogasi (arrogance). Menurut Horwath oleh Marsellisa Nindito (2018) dalam (2011) arogansi adalah sikap superioritas mendeteksi kecurangan laporan keuangan, atas hak yang dimiliki dan merasa bahwa dan penelitian Febriana (2020) dalam kontrol internal atau kebijakan perusahaan mendeteksi kecuarangan akademik. Teori tidak berlaku untuk dirinya. Menurut fraud pentagon diperkenalkan dalam literatur Abayomi \& Abayomi (2016) fraud adalah pada Horwath (2011) yang berjudul "Why penipuan atau kriminal yang dimaksudkan the Fraud Triangle is No Longer Enaugh" untuk menghasilkan keuntungan finansial yang dikembangkan oleh Jonathan Marks. atau pribadi atau seseorang dengan hal-hal Teori fraud pentagon merupakan perluasan yang dimaksudkan untuk menipu orang dari teori fraud triangle yang sebelumnya 
dikemukakan oleh Cressey, dalam teori ini perilaku kecurangan akademik mahasiswa menambahkan dua elemen fraud lainnya fakultas ekonomi di satu universitas. yaitu kompetensi (competence) dan arogansi Penelitian yang juga dilakukan Febriana (arrogance). Kompetensi (competence) yang (2020) yang menggunakan dimensi fraud dipaparkan dalam teori fraud pentagon pentagon menyatakan tekanan, peluang, memiliki makna yang serupa dengan rasionalisasi, dan kemampuan memiliki kemampuan (capability) yang sebelumnya pengaruh terhadap perilaku kecurangan dijelaskan dalam teori fraud diamond oleh akademik pada uji kompetensi. Sedangkan Wolfe \& Hermanson (2004). Lima elemen arogansi yang dimiliki mahasiswa tidak yang terdapat dalam teori fraud pentagon mendorong mahasiswa untuk melakukan diuraikan berikut: 1) Tekanan (pressure) kecurangan akademik pada uji kompetensi. merupakan dorongan atau motivasi yang dirasakan dalam diri seseorang baik berasal dari pihak internal (diri sendiri) maupun pihak eksternal (lingkungan) sehingga menyebabkan seseorang terpaksa melakukan suatu tindakan (Putri \& Amar, 2019). 2) Peluang (opportunity) merupakan kondisi yang memungkinkan untuk melakukan tindak kecurangan (Apriani et al., 2017). 3) Rasionalisasi (rationalization) dapat diartikan sebagai suatu sikap atau anggapan pribadi bahwa kecurangan merupakan tindakan yang tidak salah (Putri \& Amar, 2019). 4) Kemampuan (capability) merupakan sifat-sifat pribadi dan kemampuan, yang memainkan peran utama dalam melakukan kecurangan. Kecurangan tidak akan terjadi tanpa orang yang tepat dengan kemampuan yang tepat dalam melakukan kecurangan (Wolfe \& Hermanson, 2004). 5) Arogansi (arogance) merupakan sikap superioritas atas hak yang dimiliki dan merasa bahwa kontrol internal atau kebijakan perusahaan tidak berlaku untuk dirinya (Horwath, 2011).

Dari hasil penelitian terdahulu mengenai kecurangan akademik yang dilakukan oleh Putri \& Amar (2019) yang menggunakan dimensi fraud triangle, yaitu bahwa tindak kecurangan akademik mahasiswa ditentukan oleh tekanan, peluang dan rasionalisasi berpengaruh positif signifikan terhadap perilaku kecurangan akademik mahasiswa Akuntansi yang ada di Fakultas Ekonomi Universitas Madura. Kemudian Penelitian yang dialakukan oleh Yudiana \& Lastanti (2016) yang menggunakan dimensi fraud diamond menyatakan bahwa tekanan memiliki pengaruh yang tidak signifikan terhadap perilaku kecurangan akademik. Sedangkan peluang, rasionalisasi dan kesempatan memiliki pengaruh yang signifikan terhadap

\section{Tekanan dan Perilaku Kecurangan Akademik}

Ruankaew (2016) menyatakan setiap pelaku harus menghadapi tekanan untuk melakukan penipuan. Tekanan yang dirasakan didefinisikan sebagai motivasi yang mengarahkan pelaku untuk terlibat dalam perilaku yang tidak etis. Meskipun seseorang dapat menunjukan motif penipuan yang berbeda, penipuan sering terjadi sebagai respons terhadap tekanan ekonomi, dan sebagian besar tekanan melibatkan kebutuhan kuangan seperti keserakahan, hidup di luar kemampuan seseorang, pengeluaran besar atau hutang pribadi, kredit buruk, kerugian finasial pribadi, dan ketidak mampuan untuk memenuhi perkiraan keuangan. Apabila dihubungkan dengan fenomena kecurangan akademik, Menurut Putri \& Amar (2019) tekanan dalam konteks kecurangan akademik merupakan dorongan maupun motivasi yang dihadapi mahasiswa dalam kesehariannya yang mempunyai hubungan dengan masalah akademik dan menyebabkan mereka memiliki tekanan yang kuat untuk mendapatkan hasil akademik yang terbaik dengan cara apapun.

\section{H1: Tekanan dalam proses akademik berpengaruh positif terhadap perilaku mahasiswa}

\section{Peluang dan Perilaku Kecurangan Akademik}

Peluang yaitu saat seseorang berada dalam kondisi melakukan tindak kecurangan dikarenakan lemahnya kondisi dan situasi sehingga seseorang bisa melakukan tindakan kecurangan tanpa penjagaan dan tidak terkena sanksi (Sihombing \& Budiartha, 2020). Penelitian 
yang dilakukan Ruankaew (2016) menjelaskan bahwa peluang yang ada dalam organisasi memiliki dampak yang besar pada keputusan individu untuk melakukan penipuan. Billy et al. (2019) menyatakan kecurangan akademik muncul ketika siswa menemukan adanya metode tertentu untuk menyontek. Hal ini sangat mudah untuk ditemukan oleh siswa, karena ada banyak sekali cara untuk melakukan kecurangan, namun kurangnya kontrol internal dari sekolah serta rendahnya intervensi dari pengajar merupakan penyebab utama peluang dapat terjadi. Metode ini juga berupa kecurangan yang dilakukan saat ujian, terkait pembuatan tugas kuliah dan plagiarisme.

H2: Peluang dalam proses akademik berpengaruh positif terhadap perilaku mahasiswa

\section{Rasionalisasi dan Perilaku Kecurangan Akademik}

Ruankaew (2016) menyatakan bahwa sikap atau rasionalisasi yang dapat diterima secara moral perlu terjadi sebelum perilaku kecurangan muncul. Penting untuk mengakui bahwa pelaku kecurangan terkadang tidak memandang tindakan pelaku kecurangan sebagai tidak etis; pelaku kecurangan hanya membenarkan tindakan mereka sebagai etis sebelum melakukan kecurangan. Dalam artian rasionalisasi adalah mencari pembenaran sebelum melakukan kejahatan, bukan sesudahnya (Putri \& Amar, 2019). Apriani et al. (2017) menjelaskan rasionalisasi yang dimaksud dalam konteks kecurangan akademik merupakan anggapan peribadi yang ada pada diri mahasiswa, dimana mahasiswa menganggap bahwa tindak kecurangan akademik bukan tindakan yang salah melainkan sudah menjadi kebiasaan setiap mahasiswa. Anggapan tersebut yang meyakinkan mahasiswa untuk melakukan tindak kecurangan akademik.

H3: Rasionalisasi dalam proses akademik berpengaruh positif terhadap perilaku mahasiswa

Kemampuan dan Perilaku Kecurangan Akademik
Menurut Wolfe \& Hermanson (2004) kemampuan didefinisikan sebagai sifat-sifat dan kemampuan yang diperlukan untuk melakukan kecurangan. Kecurangan tidak akan terjadi tanpa adanya kemampuan yang dimiliki oleh pelaku kecurangan. Beberapa elemen pendukung dalam kemampuan yaitu posisi, kecerdasar, ego, pemaksaan, kebohongan dan stres. Posisi merupakan posisi atau fungsi pelaku kecurangan tersebut dalam organisasi dapat memberikan kemampuan untuk membuat atau mengeksploitasi peluang penipuan yang tidak dimiliki orang lain. Kemudian kecerdasan, ketika pelaku kecurangan melakukan fungsinya berulang kali maka kemampuan mereka karna pengetahuan tentang proses dan kontrol fungsi semakin meningkat maka kemampuan dalam melakukan kecurangan pun akan semakin meningkat. Tanpa ego yang tinggi seseorang tidak akan mampu melakukan suatu tindak kecurangan. Dengan ego juga pelaku kecurangan mampu melakukan pemaksaan kepada orang lain untuk melakukan atau menyembunyikan kecurangan yang telah dilakukan. Pelaku kecurangan juga akan melakukan kebohongan untuk menghindari deteksi kecurangan. oleh karna itu pelaku harus mengelola stres karena kecurangan yang dilakukan dapat memicu stres (Wolfe \& Hermanson, 2004).

\section{H4: Kemampuan dalam proses akademik berpengaruh positif terhadap perilaku mahasiswa}

\section{Arogansi dan Perilaku Kecurangan Akademik}

Menurut Marks (2010) dalam Febriana (2020), arogansi merupakan superioritas atau sifat serakah yang dimiliki oleh pelaku kecurangan. pelaku kecurangan yakin bahwa peraturan atau kebijakan organisasi yang ada tidak berlaku kepada mereka. Pelaku kecurangan ini benar-benar mengabaikan konsekuensi dari tindakan yang telah mereka lakukan. Menurut Horwath (2011) arogansi merupakan sikap superioritas atas hak yang dimiliki dan merasa bahwa kontrol internal atau kebijakan perusahaan tidak berlaku untuk dirinya. dan arogansi merupakan sifat 
kurangnya hati nurani yang merupakan sikap superioritas atau adanya sifat congkak pada seseorang yang percaya bahwa pengendalian internal tidak dapat diberlakukan secara pribadi (Aprilia, 2017).

H5: Arogansi dalam proses akademik berpengaruh positif terhadap perilaku mahasiswa

\section{Metode, Data dan Analisis}

Objek dalam penelitian ini adalah mahasiswa di 15 universitas di Bandar Lampung. Pengambilan objek tersebut dipertimbangkan berdasarkan mahasiswa yang telah mendapatkan teori mengenai etika yang diterima pada matakuliah Etika Profesi atau matakuliah yang berkaitan dengan Etika. Menurut kamus besar bahasa Indonesia (KBBI), etika memiliki arti, yaitu ilmu tentang apa yang baik dan apa yang buruk dan tentang hak dan kewajiban moral (akhlak). Seorang mahasiswa harus mengerti etika berperilaku baik dan buruk agar terbiasa didalam dunia kerja untuk melakukan tugas dan tanggung jawab dengan menjunjung tinggi nilai etika.

Penelitian ini menggunakan pendekatan kuantitatif. Jenis data yang digunakan dalam penelitian ini adalah data primer yaitu sumber data yang diperoleh langsung dari lokasi penelitian dengan memberikan data kepada pengumpul data (Sugiyono (2012:156) dalam Putri \& Amar 2019). Data primer diperoleh dari jawaban kuesioner dengan mendistribusikan secara online melalui Google Form kepada mahasiswa di 15 universitas di Bandar Lampung.

Dalam penelitian ini metode yang digunakan dalam pengambilan sampel adalah purposive sampling, di mana teknik pengambilan sampel dilakukan dengan pertimbangan tertentu dengan tujuan untuk memberikan informasi yang maksimal (Putri \& Amar, 2019). Kriteria yang diterapkan dalam penelitian ini adalah sebagai berikut:

1. Mahasiswa aktif di 15 universitas di Bandar Lampung.

2. Mahasiswa di 15 universitas yang telah atau sedang menempuh mata kuliah Etika Profesi atau mata kuliah yang berkaitan dengan Etika.

Teknik pengumpulan data yang digunakan dalam penelitian ini adalah survey. Alat yang digunakan dalam pengumpulan data yaitu kuesioner dengan mendistribusikan secara online menggunakan google form kepada responden. Skala pengukuran yang digunakan untuk variabel dalam penelitian ini menggunakan skala likert dengan rincian sebagai berikut: (1) Sangat Tidak Setuju (2) Tidak Setuju (3) Netral (4) Setuju (5) Sangat Setuju. Analisis data yang digunakan analisis regresi linear berganda dengan penungujian uji validitas dan uji reliabilitas.

\section{Hasil dan Diskusi}

Kuesioner yang telah dibagikan melalui google form memperoleh 329 responden. 273 responden yang sesuai dengan kriteria yang telah ditetapkan dalam penelitian ini.

\section{Tabel 1 Hasil Pengumpulan Data}

\section{Kuesioner}

\begin{tabular}{|l|c|}
\hline \multicolumn{1}{|c|}{ Keterangan } & Jumlah \\
\hline $\begin{array}{l}\text { Total kuesioner yang } \\
\text { terkumpul }\end{array}$ & 329 \\
\hline $\begin{array}{l}\text { Kuesioner yang tidak sesuai } \\
\text { dengan kriteria }\end{array}$ & 56 \\
\hline $\begin{array}{l}\text { Kuesioner yang sesuai } \\
\text { dengan kriteria }\end{array}$ & 273 \\
\hline
\end{tabular}

Sumber: Data Primer Penelitian 2020

Tabel 2 Hasil Uji Validitas

\begin{tabular}{|c|c|c|c|}
\hline Variabel & $\begin{array}{c}\text { Ite } \\
\text { m }\end{array}$ & $\begin{array}{c}\text { Sig. } \\
(2- \\
\text { tailed } \\
)\end{array}$ & $\begin{array}{c}\text { Keteranga } \\
\mathbf{n}\end{array}$ \\
\hline \multirow{6}{*}{ Tekanan } & $\mathrm{T} 1$ & 0.000 & Valid \\
\hline & $\mathrm{T} 2$ & 0.000 & Valid \\
\hline & $\mathrm{T} 3$ & 0.005 & Valid \\
\hline & $\mathrm{T} 4$ & 0.000 & Valid \\
\hline & T5 & 0.000 & Valid \\
\hline & T6 & 0.000 & Valid \\
\hline \multirow{3}{*}{ Peluang } & P1 & 0.000 & Valid \\
\hline & P2 & 0.000 & Valid \\
\hline & P3 & 0.000 & Valid \\
\hline
\end{tabular}




\begin{tabular}{|c|r|r|c|}
\hline & P4 & 0.000 & Valid \\
\hline \multirow{4}{*}{$\begin{array}{c}\text { Rasionalisa } \\
\text { si }\end{array}$} & R1 & 0.000 & Valid \\
\cline { 2 - 4 } & R2 & 0.000 & Valid \\
\cline { 2 - 4 } & R3 & 0.000 & Valid \\
\cline { 2 - 4 } & R4 & 0.000 & Valid \\
\cline { 2 - 4 } & R5 & 0.000 & Valid \\
\hline \multirow{4}{*}{ Kemampuan } & 0.000 & Valid \\
\cline { 2 - 4 } & K1 & 0.000 & Valid \\
\cline { 2 - 4 } & K2 & 0.000 & Valid \\
\cline { 2 - 4 } & K3 & 0.000 & Valid \\
\cline { 2 - 4 } & K4 & 0.000 & Valid \\
\cline { 2 - 4 } & K5 & 0.000 & Valid \\
\hline Arogansi & A2 & 0.002 & Valid \\
\hline \multirow{4}{*}{$\begin{array}{c}\text { Kecurangan } \\
\text { Akademik }\end{array}$} & KA1 & 0.000 & Valid \\
\cline { 2 - 4 } & KA2 & 0.000 & Valid \\
\cline { 2 - 4 } & KA3 & 0.000 & Valid \\
\cline { 2 - 4 } & KA4 & 0.000 & Valid \\
\cline { 2 - 4 } & KA5 & 0.000 & Valid \\
\cline { 2 - 4 } & KA6 & 0.000 & Valid \\
\hline
\end{tabular}

Sumber: Data Diolah 2020

Tabel 3 Hasil Uji Reliabilitas

\begin{tabular}{|c|c|}
\hline $\begin{array}{c}\text { Cornbach's } \\
\text { Alpha }\end{array}$ & Keterangan \\
\hline .932 & Reliabel \\
\hline \multicolumn{2}{|l}{ Sumber: Data Diolah 2020} \\
\hline
\end{tabular}

Tabel 4 Hasil Analisis Regresi Linear

\section{Berganda}

\begin{tabular}{|l|c|l|l|}
\hline \multirow{2}{*}{ Model } & $\begin{array}{c}\text { Unstandardized } \\
\text { Coefficients }\end{array}$ & Sig. & Kesimpulan \\
\cline { 2 - 4 } & $\mathrm{B}$ & .002 & \\
\hline Tekanan & .334 & .739 & $\begin{array}{c}\mathrm{H}_{1} \text { tidak } \\
\text { terdukung }\end{array}$ \\
\hline Peluang & 5.623 & .000 & $\begin{array}{c}\mathrm{H}_{2} \\
\text { terdukung }\end{array}$ \\
\hline Rasionalisasi & 4.922 & .000 & $\begin{array}{c}\mathrm{H}_{3} \\
\text { terdukung }\end{array}$ \\
\hline Kemampuan & 7.559 & .000 & $\begin{array}{c}\mathrm{H}_{4} \\
\text { terdukung }\end{array}$ \\
\hline Arogansi & -.584 & .560 & $\begin{array}{c}\mathrm{H}_{5} \text { tidak } \\
\text { terdukung }\end{array}$ \\
\hline
\end{tabular}

Sumber: Data Diolah 2020
Berdasarkan hasil analisis regresi linear berganda pada tabel 4.5 diperoleh koefisien untuk variabel independen $X_{1}=$ $0,334, X_{2}=5,623, \quad X_{3}=4,922, X_{4}=7,559$, $\mathrm{X}_{5}=-0,584$ dengan konstanta sebesar 3,054. Dengan demikian dapat dihasilkan persamaan regresi linear berganda sebagai berikut:

$$
\mathrm{Y}=3,054+0,334+5,623+4,922+
$$

$7,559-0,584+\mathrm{e}$

Berdasarkan Tabel 4, hasil koefisien variabel tekanan sebesar 0,334 dan signifikansi sebesar 0,739 $(p>0,05)$. Dengan demikian dapat diartikan bahwa tekanan dalam proses akademik tidak berpengaruh terhadap perilaku mahasiswa (H1 tidak terdukung). Hasil penelitian sejalan dengan hasil yang ditemukan oleh Adrianus et al (2019) dan Yudiana \& Lastanti (2016) bahwa tekanan tidak berpengaruh terhadap perilaku kecurangan akademik. Dalam penelitian ini tekanan dalam proses akademik tidak berpengaruh terhadap perilaku mahasiswa. Hal ini berarti bahwa mahasiswa tidak memiliki tekanan untuk melakukan kecurangan akademik. Mahasiswa merasa tugas kuliah tidak terlalu banyak dan sulit untuk dikerjakan, kemudian dalam kondisi apapun mahasiswa tetap bisa mendapatkan nilai yang mereka inginkan. Tingkat indeks prestasi terkadang bukan hal yang penting bagi mahasiswa dan orang tua tidak menuntut mereka untuk memiliki indeks prestasi yang bagus. Kemudian persaingan nilai dengan teman tidak begitu penting dan mereka bisa membagi waktu untuk mengerjakan tugas kuliah dan kegiatan kuliah (organisasi, kepanitiaan, dsb).

Hipotesis 2 yang memprediksi hubungan antara peluang dan perilaku kecurangan akademik menunjukan hasil koefisien variabel sebesar 5,623 dan signifikansi sebesar 0,000 $(p<0,05)$ oleh karna itu $\mathrm{H} 2$ terdukung. Dengan demikian dapat diartikan bahwa peluang dalam proses akademik berpengaruh positif terhadap perilaku mahasiswa. Penelitian ini sejalan dengan penelitian yang dilakukan Febriana (2020), Putri \& Amar 
(2019), Sihombing \& Budiartha (2020), Mahasiswa memiliki kemampuan dapat Apriani et al (2017), Fransiska \& Utamimenekan rasa bersalah atau bahkan tidak (2019), Murdiansyah et al. (2017), danmerasa bersalah setelah melakukan Yudiana \& Lastanti (2016). Dalam penelitiankecurangan. Kemudian mahasiswa memiliki ini peluang dalam proses akademikkecerdasan sehingga menimbulkan rasa berpengaruh terhadap perilaku mahasiswapercaya diri dan memiliki ego yang tinggi karena kemajuan teknologi memudahkansehingga dapat melakukan pemaksaan kepada mahasiswa mencari jawaban dan copy pasteorang lain untuk ikut melakukan kecurangan tanpa menyebutkan sumbernya. Ketika ujianakademik. Mahasiswa juga dapat memahami mahasiswa mendapatkan posisi yang tepatkriteria penilaian dosen dan dapat memikirkan untuk melakukan kecurangan akademikcara melakukan kecurangan akademik dengan dengan leluasa dan pengawas tidak menjagapeluang yang dimiliki.

ujian dengan ketat. Kemudian mahasiswa juga Hasil pengujian Hipotesis 5 menunjukkan mendapatkan jawaban tugas kuliah dari teman atau kakak tingkat.

Hasil pengujian Hipotesis 3 menunjukkan nilai koefisien variabel sebesar 4,922 dan signifikasi sebesar 0,000 $(p<0,05)$. Dengan demikian dapat diartikan bahwa rasionalisasi dalam proses akademik berpengaruh positif terhadap perilaku mahasiswa (H3 terdukung). Hasil penelitian ini selaras dengan penelitian yang dilakukan Febriana (2020), Putri \& Amar (2019), Andrianus et al (2019), Sihombing \& Budiartha (2020), Apriani et al (2017), Fransiska \& Utami (2019), Murdiansyah et al (2017) dan Yudiana \& Lastanti (2016) dimana rasionalisasi berpengaruh signifikan terhadap perilaku kecurangan akademik. Hal ini menunjukkan bahwa semakin tinggi rasionalisasi yang dimiliki mahasiswa, maka semakin tinggi kemungkinan mahasiswa melakukan kecurangan akademik. Di mana mereka merasionalisasikan bahwa orang lain juga pernah melakukan kecurangan akademik, maka mereka juga melakukan kecurangn akademik. kemudian mereka terbiasa melakukan kecurangan akademik sejak di 4.
bangku SMA. Fakultas yang tidak memberikan sanksi tegas bagi mahasiswa yang melakukan kecurangan dan jarang mendeteksi adanya praktik kecurangan. kemudian bagi mereka kecurangan akademik yang dilakukan tidak merugikan orang lain.

Nilai koefisien variabel untuk Hipotesis 4 sebesar 7,559 dan signifikasi sebesar 0,000 $(p<0,05)$. Dengan demikian dapat diartikan bahwa kemampuan dalam proses akademik berpengaruh positif terhadap perilaku mahasiswa (H4 terdukung). Penelitian ini sejalan dengan penelitian Febriana (2020), Fransiska \& Utami (2019), Murdiansyah et al (2017) dan Yudiana \& Lastanti (2016). nilai koefisien variabel sebesar $-0,584$ dan signifikan sebesar 0,560 ( $p>0,05)$. Dengan demikian dapat diartikan bahwa arogansi dalam proses akademik tidak berpengaruh terhadap perilaku mahasiswa (H5 tidak terdukung). Hasil penelitian ini selaras dengan penelitian yang dilakukan oleh Fitriana (2020) dan Muhsin et al (2018) di mana arogansi tidak mendorong mahasiswa untuk melakukan kecurangan akademik. Crowe (2011) menyebutkan salah satu faktor seseorang melakukan kecurangan yaitu karena adanya sikap arogansi yang dimiliki. Mahasiswa tidak memiliki egois yang tinggi untuk melakukan kecurangan akademik. Mahasiswa tidak memiliki sikap yang suka membully, kemudian mahasiswa tidak dapat menekan teman untuk memberikan jawaban pada saat ujian. Serta mahasiswa tidak memiliki rasa takut akan kehilangan status dan posisi jika tidak melakukan kecurangan.

\section{Kesimpulan, Keterbatasan, dan Saran}

\section{Kesimpulan}

Berdasarkan hasil dan pembahasan maka dapat disimpulkan bahwa tekanan dalam proses akademik tidak berpengaruh positif terhadap perilaku mahasiswa. Hal ini dikarenakan tekanan tidak mendorong mahasiswa untuk melakukan tindak kecurangan akademik. Peluang dalam proses akademik berpengaruh positif terhadap perilaku mahasiswa. Hal ini dikarenakan mahasiwa memiliki peluang yang besar sehingga mampu melakukan tindak kecurangan tanpa terkena sanksi. Rasionalisasi dalam proses akademik 
berpengaruh positif terhadap perilaku kecurangan akademik di lingkungan mahasiswa. Hal ini dikarenakan pemikiran Universitas. rasionalisasi terhadap perilaku kecurangan akademik yang semakin besar, makaDAFTAR PUSTAKA kecurangan akademik semakin dianggap sebagai suatu hal yang umum dilakukan olehAbayomi, S. O., \& Abayomi, S. O. (2016). mahasiswa. Kemampuan dalam proses akademik berpengaruh positif terhadap perilaku mahasiswa. Hal ini dikarenakan kemampuan dalam kecurangan akademik yang dimiliki mahasiswa semakin besar, maka semakin mempermudah mahasiswa untuk melakukan tindak kecurangan akademik. Arogansi dalam proses akademik tidak berpengaruh positif terhadap perilaku mahasiswa. Hal ini dikarenakan sikap arogansi yang dimiliki mahasiswa tidak mempengaruhi mahasiswa untuk melakukan tindak kecurangan akademik.

Tekanan, peluang, rasionalisasi, kemampuan dan arogansi dalam proses akademik secara simultan berpengaruh terhadap perilaku mahasiswa.

\section{Keterbatasan dan Saran}

Penelitian ini tidak terlepas dari beberapa keterbatasan. Pertama, penelitian ini belum bisa membuktikan adanya pengaruh tekanan dan arogansi terhadap perilaku kecurangan akademik. kedua, hasil penelitian terbatas untuk Universitas yang berada di Kota Bandar Lampung sehingga hasilnya belum dapat menggeneralisasi seluruh Universitas di luar daerah. Penelitian selanjutnya diharapkan dapat menguji kembali berdasarkan inkonsistensi hasil dari penelitian ini dan penelitian sebelumnya, dan dapat memperluas sampel pada Universitas lain yang bisa menggeneralisasi hasil di seluruh Universitas yang ada di Indonesia.

Kecurangan akademik sangat erat kaitannya dengan perilaku mahasiswa dalam menjalankan aktivitasnya pada perkuliahan. Sampai saat ini masih banyak mahasiswa yang melakukan tindakan plagiarisme, mencontek, mengcopy paste dari internet, bekerjasama dengan teman pada saat ujian, memalsukan sesuatu yang berhubungan dengan akademik. Hal ini dapat menjadi kebiasaan yang dapat berujung pada kecurangan yang bisa dilakukan dalam dunia kerja. Oleh karna itu, Universitas diharapkan dapat memberikan sanksi tegas bagi mahasiswa yang melakukan tindakan Personal Ethics and Fraudster Motivation: The Missing Link in Fraud Triangle and Fraud Diamond Theories. International Journal of Academic Research in Business and Social Sciences. https://doi.org/10.6007/ijarbss/v6-i2/2020

Apriani, Sujana, \& Sulindawati. (2017). Pengaruh Pressure, Opportunity, dan Rationalization terhadap Perilaku Kecurangan Akademik (Studi Empiris : Mahasiswa Akuntansi Program S1 Universitas Pendidikan Ganesha). Jurnal Ilmiah Mahasiswa Akuntansi Univeristas Pendidikan Ganesha.

Becker, D., Connolly, J., Lentz, P., \& Morrison, J. (2006). Using the Business Fraud Triangle to Predict Academic Dishonesty among Business Students. Academy of Educational Leadership Journal.

Billy, B., Andrianus, A., Yuliati, R., \& Adelina, Y. E. (2019). KECURANGAN AKADEMIK PADA MAHASISWA AKUNTANSI BERDASARKAN PERSPEKTIF FRAUD DIAMOND. Ekspansi: Jurnal Ekonomi, Keuangan, Perbankan Dan Akuntansi. https://doi.org/10.35313/ekspansi.v11i2.1 346

Devi Lestari Pramita Putri, Siti Salama Amar. (2019). ANALISIS FRAUD DALAM PROSES AKADEMIK TERHADAP KUALITAS MAHASISWA AKUNTANSI. Jurnal Ilmiah Akuntansi Dan Finansial Indonesia. https://doi.org/10.31629/jiafi.v3i1.1585

Febriana, N. R. (2020). ANALISIS PENGARUH DIMENSI FRAUD PENTAGON TERHADAP PERILAKU KECURANGAN AKADEMIK MAHASISWA PADA UJI KOMPETENSI. Jurnal Ilmiah Mahasiswa FEB Universitas Brawijaya. 
Fransiska, I. S., \& Utami, H. (2019). Perilaku

Kecurangan Akademik Mahasiswa:

Perspektif Fraud Diamond Theory. Jurnal Akuntansi

Aktual. https://doi.org/10.17977/um004v6i22019p 316

Horwath, C. (2011). Why the Fraud Triangle is No Longer Enough. Www.Crowe.Com.

Howe, M. A., \& Malgwi, C. A. (2006). Playing the Ponies: A \$5 Million Embezzlement Case. Journal of Education for Business. https://doi.org/10.3200/JOEB.82.1.27-33

Matthew, K., Patrick, K., \& Denise, K. (2013). The effects of fraudulent procurement practices on public procurement performance. International Journal of Business and Behavioral Sciences.

Murdiansyah, I., Sudarman, M., \& Nurkholis. (2017). Pengaruh dimensi fraud diamond terhadap perilaku kecurangan akademik. Jurnal Akuntansi Aktual.

Ruankaew, T. (2016). Beyond the Fraud Diamond. International Journal of Business Management \& Economic Research.

Sihombing, M., \& Budiartha, I. K. (2020). Analisis Pengaruh Fraud Triangle Terhadap Kecurangan Akademik (Academic Fraud ) Mahasiswa Akuntansi Universitas Udayana. E-Jurnal Akuntansi. https://doi.org/10.24843/eja.2020.v30.i02. p07

Undang-Undang No. 12 Tahun 2012 tentang Pendidikan Tinggi.

Wolfe, D. T., \& Hermanson, D. R. (2004). The Fraud Diamond: Considering the Four Elements of Fraud. CPA Journal. https://doi.org/DOI:

Yudiana, A. P., \& Lastanti, H. S. (2016). Analisis pengaruh dimensi fraud diamond terhadap perilaku kecurangan akademik mahasiswa fakultas ekonomi. Seminar Nasional Dan Call Paper Fakultas 